\title{
Do We Really Need Carbohydrates? A Mini Review on Obesity and Diseases
}

ISSN: 2578-0263

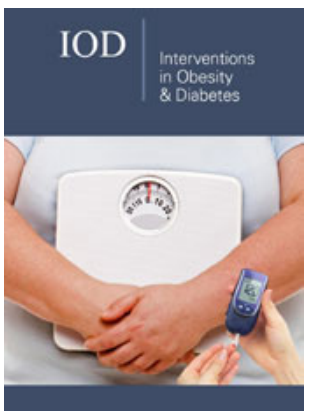

*Corresponding author: Hanan S Abushwereb, Pharmacology and Clinical Pharmacy Department, University of Tripoli, Faculty of Pharmacy, Libya

Submission: 漹 February 15, 2021

Published: March 18, 2021

Volume 5 - Issue 1

How to cite this article: Hanan S Abushwereb. Do We Really Need Carbohydrates? A Mini Review on Obesity and Diseases. Interventions Obes Diabetes 5(1). IOD. 000605. 2021

DOI: 10.31031/IOD.2021.05.000605

Copyright@ Hanan S Abushwereb. This article is distributed under the terms of the Creative Commons Attribution 4.0 International License, which permits unrestricted use and redistribution provided that the original author and source are credited.

\author{
Hanan S Abushwereb* \\ Pharmacology and Clinical Pharmacy Department, Libya
}

\begin{abstract}
Obesity has become a disease of the age, and there are many innovative methods used to fight obesity, as every new day we find innovations in the world of slimming and weight loss. Obesity known to increase the risk of a number of health disorders such as heart, diabetes and cancer, in addition to reducing people's life expectancy. It is well known that sugar and carbohydrates in general give energy to the body. Recently, nutrition scientists stating that excess sugar is not burned, and therefore the body does not need it to generate energy, and it is often converted into other natural substances such as fat that accumulate in large quantities in the body. It is considered as the main cause of serious and chronic diseases that harm human life over time. Therefore, to combat this phenomenon, which is obesity, efforts should be intensified with more studies calling for modern diets that focus on reducing refined and harmful carbohydrates without depriving the body of reaching a state of satiety and activity. By prescribing it to lose excessive body weight, reduce diseases and infections that affect the quality of life to reach healthy bodies and minds enjoying vitality and intelligence.
\end{abstract}

Keywords: Carbohydrates; Insulin resistance; Metabolic syndrome; Glycemic index; Obesity; Diseases

\section{Introduction}

Carbohydrates are among the main food groups, along with proteins and fats. Many food groups fall into the carbohydrate group, such as sugars or starches, and are composed primarily of hydrogen, oxygen, and carbon. One of the most important functions of carbohydrates is energy production. Where, after digestion, it turns into mono-glucose. Which in turn nourishes the cells of the body. As carbohydrates convert faster and easier to glucose than proteins and fats, so they are the main source of energy that the body needs to carry out vital functions. The prevailing belief persisted by people who consider it as the main body's food source of energy [1]. No one can deny the importance of the presence of carbohydrates in the human diet for the body to perform its vital functions, just as we cannot also deny that carbohydrates have serious harm that threatens human life. With the rapid development and change in lifestyle and the resort to fast and ready-made foods containing high levels of carbohydrates and simple carbohydrates such as bread, sugars and starches [2,3]. We have seen many unknown-source diseases, symptoms and infections that have recently appeared on the human body and its health, which disturbed and bothered him. As in recent years, the introduction of high rates of processed carbohydrates has increased in food products in the world markets. Whether are candies, starch, or local corn syrup, with juices, drinks sweets and baked goods, which led to an increase in diseases and infections that now we see a day even in children and young people. Diseases such as overweight or obesity, insulin resistance, fatty liver [4,5], high triglycerides, diabetes, Alzheimer's, gout [6], cancers [7,8] and the list goes on. One of these dangerous and causative factors is insulin resistance [9]. The majority of people with accumulated belly fat have a condition called insulin resistance [9]. A condition precedes diabetes in which the body's cells reject or block insulin. Since the cells' sensitivity or sensing to insulin is low, it will stimulate the work of the pancreas to make more. People who have insulin resistance have four to five times the amount of insulin in their bodies even when they are fasting. One of the symptoms of insulin resistance is cravings for sweets, dissatisfaction after eating that cannot last for long without hunger [10,11]. Good mood with eating, fluid retention, frequent urination at night, polycystic ovary syndrome or polycystic ovaries [12]. On the other hand, dietary factors play an important role in the development of chronic heart disease through their effects on body weight and serum lipid levels [13-15]. It is widely accepted that dietary carbohydrate intakes increase the risk of stroke. Recently, 
several studies have raised the issue of the relationship between carbohydrate related factors (Glycemic Index (GI) and Glycemic Load (GL)) and chronic heart disease risk factors [16]. In general, more refined or processed carbohydrates have a higher GI. This in turns makes cells in muscles, fat, and liver do not respond well to insulin and cannot use glucose from blood for energy. Over time, the blood sugar levels go up and the pancreas makes more insulin ending to insulin resistance.

So far, dealing with insulin resistance seems the only way to fix a slow and stubborn metabolism, and the solution is to follow a lowcarb diet and stay away from substances that would raise the blood sugar level [17]. However, the body still needs very little complex carbohydrates that come from vegetables, green leaves and grains such as legumes and seeds, not simple carbohydrates such as sugars and starch, which quickly turn into blood sugar and thus lead to the health problems we see today [18]. Things do not stop here, as "Covid-19" the virus that baffled the world in 2020 is still spreading rapidly among people, causing shortness of breath and severe acute pneumonia that leads to death. Covid-19 affects patients who complain of obesity are more likely to die from complications from the disease compared to people who are of a healthy weight [19]. As a recent study revealed that obesity, increases the risk of death by nearly 50 percent among "Covid-19" patients who suffer from obesity and the prospective vaccine may be less effective in protecting them from infection with the emerging corona virus [19]. The excessive intake of carbohydrates downregulate the anti-aging gene with implications to increased risk of COVID-19 and success of vaccines [20-22]. In addition, its severity linked to age, chronic diseases and the strength of the body's immune system; all of these factors increase the risk. Thus, the nutritional diets, lifestyles and exercise are required to activate the anti-aging gene that is critical to prevent obesity and diabetes [22]. This mini review comes as a number of international research efforts are continuing to combat obesity, given its worrisome health consequences.

\section{Summary}

Despite the many benefits of carbohydrates and being the main source of energy in the human body, excessive intake of carbohydrates may cause some damage that may negatively affect human health, so carbohydrates must be consumed in quantities appropriate to the body's energy needs. The serious damage that carbohydrates may cause is weight gain and diabetes. It may cause insulin resistance of cells and thus the survival of sugar in the blood, which increases the possibility of diabetes, so it is necessary to eat complex sugars that raise sugar slowly in the blood and lower it slowly, which maintains the level of sugar normally and avoids the risk of diabetes and what follow of diseases. Hence, the need for a revolution in the world of nutrition and the re-concept of nutritional science has become an urgent and necessary matter. In addition, need to understanding the importance of carbohydrates and reducing their intake, especially in children and young ages. It has become a very important matter to modify the food culture and return to nature to build healthy bodies free from diseases and infections. Increasing or boosting the immune system to fight the disease by decreasing insulin and sugar levels in the blood.
Whereas, carbohydrates divided into two types, simple and complex. Through our understanding of the classification of carbohydrates, obtaining complex carbohydrates such as vegetables and green leaves is necessary for the metabolism of the body and brain cells to obtain the necessary vitamins and not for the carb itself. Through ancient and modern studies, it became important for nutritional scientists to introduce natural healthy animal proteins and fats that ancient man used to eat since the beginning of creation, before he knew factories, manufacturing and refining of sugar and salt. It is necessary to change the lifestyle and the rapid return of nature to rectify the matter and repair what can be repaired for our bodies and the bodies of our children so that they become more intellectually and physically active, as the problem is global and is not limited to specific societies or countries. In addition, efforts should focus on raising awareness about harmful eating habits and the high demand for fast food, as well as encouraging exercise as an activity necessary to maintain fitness.

\section{References}

1. Davidson EA (2020) Carbohydrate. Encyclopedia Britannica.

2. Maria Zamarripa MS (2019) Sugar and cholesterol: The unexplained connection. Food Farmacist RD.

3. Taskinen MR, Packard CJ, Borén J (2019) Dietary fructose and the metabolic syndrome. Nutrients 11(9): 1987.

4. Bhatt HB, Smith RJ (2015) Fatty liver disease in diabetes mellitus. Hepatobiliary Surg Nutr 4(2): 101-108.

5. John JG (2016) Hepatic glucose and lipid metabolism. Diabetologia 59(6): 1098-1103.

6. Carb's, Fat Protein (2017) Fat protein carb's: Gout and uric acid. Fat Protein Carb's.

7. Wolf I, Sadetzki S, Catane R, Karasik A, Kaufman B (2005) Diabetes mellitus and breast cancer. The Lancet Oncology 6(2): 103-111.

8. Rainer KJ, Kämmerer U (2011) Is there a role for carbohydrate restriction in the treatment and prevention of cancer? Nutrition \& Metabolism 8: 75.

9. (2020) Insulin Resistance. WebMD, USA.

10. Watson NA, Dyer KA, Buckley JD, Brinkworth GD, Coates AM, et al. (2018) Reductions in food cravings are similar with low-fat weight loss diets differing in protein and carbohydrate in overweight and obese adults with type 2 diabetes: A randomized clinical trial. Nutr Res 57: 56-66.

11. Myers CA, Martin CK, Apolzan JW (2018) Food cravings and body weight: A conditioning response. Curr Opin Endocrinol Diabetes Obes 25(5): 298-302.

12. Dumesic DA, Oberfield SE, Victorin ES, Marshall JC, Laven JS, et al. (2015) Scientific statement on the diagnostic criteria, epidemiology, pathophysiology, and molecular genetics of polycystic ovary syndrome. Endocr Rev 36(5): 487-525.

13. Dow CA, Thomson CA, Flatt SW, Sherwood NE, Pakiz B, et al. (2013) Predictors of improvement in cardiometabolic risk factors with weight loss in women. J Am Heart Assoc 2(6): e000152.

14. Yunsheng M, Chiriboga DE, Olendzki BC, Li W, Leung K, et al. (2006) Association between carbohydrate intake and serum lipids. Journal of the American College of Nutrition 25(2): 155-163.

15. Kevin MC, Rains TM, Kaden VN, Raneri KR, Davidson MH (2007) Effects of a reduced-glycemic-load diet on body weight, body composition, and cardiovascular disease risk markers in overweight and obese adults. The American Journal of Clinical Nutrition 85(3): 724-734. 
16. Mirrahimi A, de Souza RJ, Chiavaroli L, Sievenpiper Jl, Beyene J, et al. (2012) Associations of glycemic index and load with coronary heart disease events: A systematic review and meta-analysis of prospective cohorts. J Am Heart Assoc 1(5): e000752.

17. Huntriss RM, Campbell M, Bedwell C (2017) The interpretation and effect of a low-carbohydrate diet in the management of type 2 diabetes: A systematic review and meta-analysis of randomised controlled trials. European Journal of Clinical Nutrition 72(3): 311-325.

18. Hamdy O, Tasabehji MW, Elseaidy T, Tomah S, Ashrafzadeh S, et al. (2018) Fat versus carbohydrate-based energy-restricted diets for weight loss in patients with type 2 diabetes. Curr Diab Rep 18(12): 128.
19. (2021) The Extraordinary meeting of the Strategic Advisory Group of Experts on immunization (SAGE). WHO reference number: WHO/2019CoV/vaccines/SAGE background/2020, Switzerland.

20. Martins IJ (2016) Anti-aging genes improve appetite regulation and reverse cell senescence and apoptosis in global populations. Advances in Aging Research 5(1): 9-26.

21. Martins IJ (2017) Single gene inactivation with implications to diabetes and multiple organ dysfunction syndrome. J Clin Epigenet 3(3): 24.

22. Martins IJ (2020) COVID-19 infection and anti-aging gene inactivation. Acta Scientific Nutritional Health 4(5): 1-2.

For possible submissions Click below: 